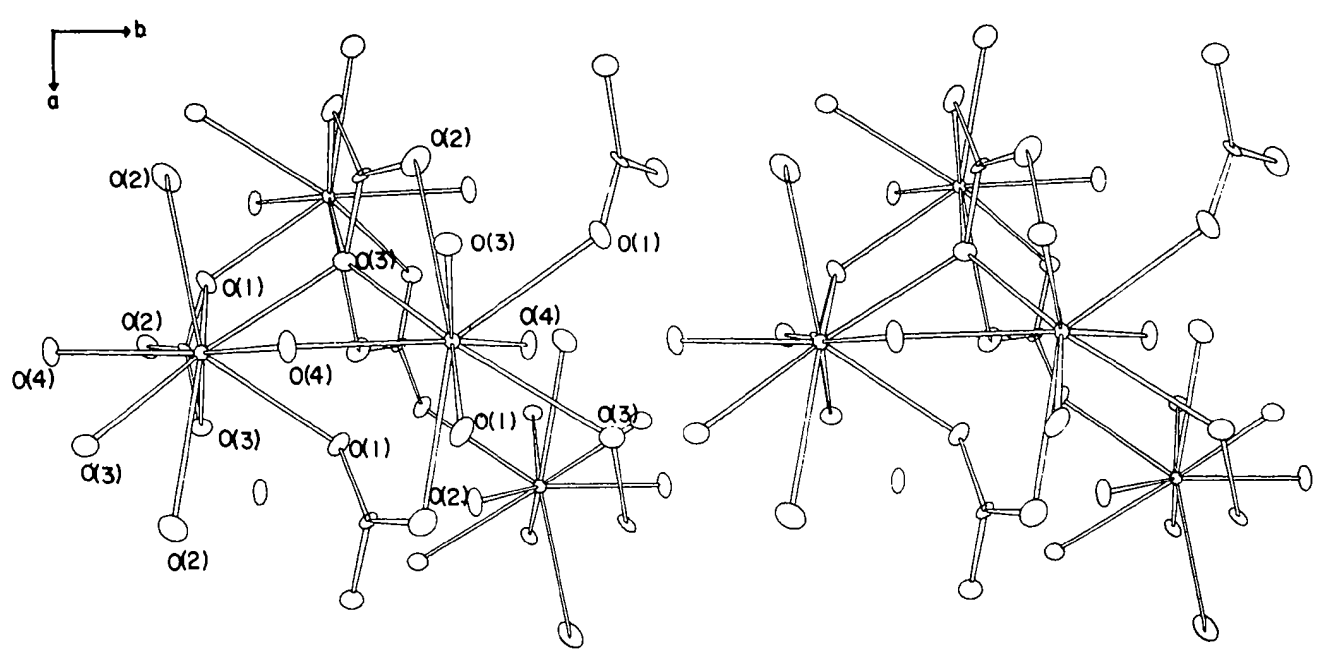

Fig. 2. Stereo view of $\mathrm{YOHCO}_{3}$.

Discussion. The structure of $\mathrm{NdOHCO}_{3}$ has been reported by Christensen (1973). The structure is hexagonal, space group $P \overline{6}$. The Nd is nine-coordinate with a coordination polyhedron shaped like a tricapped trigonal prism. $\mathrm{YOHCO}_{3}$ is orthorhombic, space group $P 2_{1} 2_{1} 2_{1}$. The $\mathrm{Y}$ is also nine-coordinate (Fig. 1), but its coordination polyhedron is a monocapped square antiprism. This polymorphism may be due to the relative size of $\mathrm{Y}$ versus $\mathrm{Nd}$. Two other major differences exist between the structures. First, in the case of Nd the coordination polyhedron contains three hydroxyl groups; the $\mathrm{Y}$ only contains two. And secondly, the carbonate ion in the $\mathrm{Y}$ structure is bidentate to two different metal atoms; in the $\mathrm{Nd}$ structure the carbonate ion is bidentate to only one metal. The C-O distances are in good agreement with the $1.28 \AA$ found in many other carbonate structures. The angles of the carbonate deviate markedly from $120^{\circ}$. This can be explained by the fact that the carbonate ion, which is bidentate to two different metals, causes two of the angles to be 118.3 and $118.7^{\circ}$ while the third is $122.8^{\circ}$. The metalto-oxygen distances can be divided into three groups. The hydroxyl distances are the shortest, 2.236 (6) and $2 \cdot 252$ (5) $\AA$. The metal-to-oxygen distances for the carbonate ion have five bonds approximately $2.45 \AA$ and two longer distances of 2.616 (7) and 2.615 (6) $\AA$. There is a tenth metal-to-oxygen distance of 2.94 (8) $\AA$.
This metal-to-oxygen distance is too long to be considered as part of the $\mathrm{Y}$ coordination sphere. The hydroxyl group is 2.895 (9) $\AA$ from O(1) and 2.698 (8) $\AA$ from $\mathrm{O}(3)$, which indicates possible hydrogen bonds. The $\mathrm{O}(4)-\mathrm{O}(1)$ bond distance is supported by the $\mathrm{OH}$ stretching frequency of $3495 \mathrm{~cm}^{-1}$ in the Raman spectra. The oxygens of the carbonate ion have two types of coordination. $\mathrm{O}(1)$ and $\mathrm{O}(2)$ are each coordinated to two $\mathrm{Y}$ and one $\mathrm{C}$. $\mathrm{O}(3)$ is coordinated to three $\mathrm{Y}$ and one $\mathrm{C}$. A drawing of the coordination polyhedron around $\mathrm{Y}$ can be seen in Fig. 1. Fig. 2 is a stereo plot of the structure.

A second type of yttrium carbonate crystals has recently been made as described above, except that the temperature in the hydrothermal reactor was $400^{\circ} \mathrm{C}$. Preliminary $\mathrm{X}$-ray diffraction studies suggest that these crystals are similar to Christensen's (1973) $\mathrm{NdOHCO}_{3}$.

This work was supported in part by the National Science Foundation (grant No. DMR-72-03131-A-03). We wish to express our thanks to Dr R. E. Davis and Dr S. H. Simonsen for the use of the Syntex $P 2_{1}$ diffractometer.

\section{Reference}

Christensen, A. N. (1973). Acta Chem. Scand. 27, 29732982.

\title{
International Union of Crystallography \\ Report of the Executive Committee for 1975
}

The Report of the Executive Committee for 1975 has been published in Acta Crystallographica, Section A [Acta Cryst. (1976), A 32, 1019-1033]. It reports as usual on the meetings and publications of the Union, the work of its Commissions, and the work of bodies not belonging to the Union but on which the Union is represented. 